\title{
HISTÓRIA, POLÍTICA E EDUCAÇÃO NO CINEMA DE BERNARDO BERTOLUCCI
}

José de Sousa Miguel Lopes ${ }^{1}$

\section{INTRODUÇÃO}

As relações existentes entre a história e o cinema não são recentes, pois datam do surgimento deste, há um século. No entanto, o seu estudo mais aprofundado remonta há apenas três décadas e ainda se encontra longe de alcançar uma situação de relativo conforto no que concerne à formulação de um arcabouço teórico sólido. Todavia, avanços foram realizados, fixando alguns conceitos fundamentais acerca dessa relação, que não podem ser ignorados pelo historiador ou por qualquer cientista social que deseje pensar a história e o cinema dentro de uma perspectiva histórico-dialética.

A princípio, considerar o cinema como fonte da história foi uma obrigação da qual se fugiu durante muito tempo, mesmo depois do paradigma aberto pela escola dos Annales, que considerava todo e qualquer registro humano como fonte potencial de produção de conhecimento histórico - em parte devido às dificuldades de preservação, acesso e visionamento dos filmes. Faltava um debate metodológico, que começou a ser desenvolvido a partir dos anos 1960 e que teve como marco a obra do historiador francês Marc Ferro nos anos 1970, que considerava tanto os filmes de ficção quanto os documentários como fontes para o estudo da história, embora cada um deles exigisse determinados cuidados por parte do historiador. A comunidade historiográfica passou quase 80 anos ignorando o cinema, tanto como fonte para a pesquisa histórica como quanto fenômeno de maior impacto no imaginário social. De nada adianta nos trancarmos em empoeirados arquivos para escreve páginas e páginas sobre um passado remoto, como monges copistas alheias à realidade que nos cerca. 
Para a maioria da população, a história que existe é aquela que se imagina. $\mathrm{Cab}^{1} \mathrm{e}$ aos historiadores, embora não apenas a eles, fazer a sociedade imaginar a história, seja com palavras ou acompanhados de imagens e sons. Certamente, dirão, o historiador não é cineasta, como também não é poeta. Mas as imagens que ele produz não precisam ser necessariamente artísticas. Devem, como suas palavras, ser claras e, dentro de uma argumentação coerente, expressar com precisão seu pensamento - e também os sentimentos que o tema mobiliza.

Como o cinema surgiu, no século $X X$, uma nova forma de representar o mundo - e para o historiador, uma nova forma de pensar a história. Pois o olhar da câmara revelava a experiência em um mundo desconhecido, raramente registrado por documentos escritos: o mundo cotidiano, o das "pessoas comuns", registrado através da imagem viva das ruas, das fábricas, da produção agrícola, dos cabarés, das guerras.

Através de pesquisa bibliográfica, procuramos um artista que através da fusão de imagens e sons conseguisse esse exercício do "poder de evocação" do passado, alguém que tivesse um apurado olhar sobre processos históricos. Nessa busca chegamos ao italiano Bernardo Bertolucci (nascido em 1940) que, a nosso ver, reúne os fundamentos que nos propusemos analisar neste texto, a saber, suas recorrentes preocupações com temas históricos que se cruzam com a política. De sua extensa obra, vale lembrar alguns desses filmes como é o caso de "Antes da revolução" (1964), "O conformista" (1970), "A Estratégia da Aranha" (1970), "1900" (1976), "O último imperador" (1987), "Os sonhadores" (2003). Nestas quatro décadas que mediaram entre o filme "Antes da Revolução" (1964) e o filme "Os sonhadores" (2003), Bertolucci produziu um trabalho cinematográfico importante ao articular a história com a política. O cinema de Bertolucci que se baseia em obras literárias, pode ser considerado como um cinema "de classe", pela inserção de uma realidade

\footnotetext{
${ }^{1}$ Professor na Universidade do Estado de Minas Gerais. miguel-lopes@uol.com.br
} 
correspondente à do próprio autor. É uma obra que se realiza desde - e sobre a burguesia, mas também para - e contra - a burguesia.

Por outro lado, sua obra pode ser instigante para ser trabalhada no sistema educacional. Nesse sentido, ao pensarmos a relação entre Educação, História e Política somos levados a considerar que a educação deve ser vista como mediação no processo de emancipação humana pressupondo a compreensão de que o homem se constitui, dialeticamente, a partir de atividades humanas que se objetivam pelo processo de comunicação nas relações interpessoais, entre sujeitos com diferentes níveis de domínio da cultura, entendida como produção histórica e memorial elaborada pelo conjunto dos homens, e que tem como finalidade a promoção do humano no homem.

À luz do que referimos pretendemos neste texto analisar duas obras de Bertolucci pela ordem cronológica de sua realização: "Antes da revolução" (1964) e "O conformista" (1970). Em relação ao período histórico a trama de "Antes da revolução" (1964) se situa nos anos 1960 e a de "O conformista" (1970) ocorre nos anos do fascismo italiano (1921-1943). Mas antes faremos uma breve análise sobre as relações entre história e cinema. Finalizaremos nossas reflexões tecendo algumas considerações sobre o modo como os olhares nas tramas cinematográficas de Bertolucci se podem constituir como desafios para os educadores.

\section{AS RELAÇÕES ENTRE A HISTÓRIA E CINEMA}

Qualquer reflexão sobre a relação cinema-história toma como verdadeira a premissa de que todo filme é um documento, desde que corresponde a um vestígio de um acontecimento que teve existência no passado, seja ele imediato ou remoto. No entanto, isso não seria suficiente para que uma película se tornasse um documento válido para a investigação historiográfica. $\mathrm{Na}$ verdade, o conceito historiográfico de documento se relaciona fundamentalmente com dois pontos: a concepção de História do pesquisador e o valor intrínseco do documento.

Foi somente a partir da década de 1970 que o filme começou a ser visto como um possível documento para a investigação histórica. Isso se deu 
em consequência de um processo de reformulação do conceito e dos métodos da História, iniciado com o desenvolvimento da Escola dos Anais, na França. O filme, seja qual for, desde então, passou a ser encarado enquanto testemunho da sociedade que o produziu, como um reflexo - não direto e mecânico - das ideologias, dos costumes e das mentalidades coletivas.

Quando o historiador Marc Ferro defendeu a hipótese de se fazer história com o cinema, foi enfático ao autorizar toda a forma de cinema como fonte para a história:

Os historiadores já recolocaram em seu legítimo lugar as fontes de
origem popular, primeiro as escritas, depois as não escritas: o
folclore, as artes e tradições populares. Resta agora estudar o filme,
associá-lo com o mundo que o produz. Qual é a hipótese? Que o
filme, imagem ou não da realidade, documento ou ficção, intriga
autêntica ou pura invenção, é História. E qual o postulado? Que
aquilo não aconteceu (e porque aquilo não aconteceu?), as crenças,
as intenções, o imaginário do homem, são tão História quanto a
História (Ferro, 1992, p. 86)

Para Ferro, portanto, não se trata apenas de autorizar a fonte cinematográfica como mera auxiliar na confirmação de outras fontes, mas de considerá-la como portadora de uma problemática historiográfica própria, voltada para a análise dos filmes para além de seu caráter documentário.

Podemos compreender que desde então o filme (bem como a canção popular, as revistas semanais e outros produtos de cultura e entretenimento da sociedade de massas) passou a ser visto como parte importante, senão preponderante, na reprodução do imaginário social. O cinema pode ser considerado fonte privilegiada para compreender as emoções, os medos e as esperanças de uma época.

Pode-se afirmar que o "filme histórico", como detentor de um discurso sobre o passado, coincide com a História no que concerne à sua condição discursiva. Segundo Hayden White (2010, p. 219):

\footnotetext{
Nenhuma história, visual ou verbal, "espelha" todos ou mesmo a maior parte dos acontecimentos ou cenas do que ela se propõe relatar, e isso também é verdade até mesmo para mais estreitamente restrita "micro história". Toda história escrita é produto de um processo de condensação, deslocamento, simbolização e qualificação, exatamente igual àqueles usados na produção de um a representação fílmica. É apenas o meio que difere não a maneira pela qual as mensagens são produzidas.
} 
Os "filmes históricos", ou seja, aqueles em que o seu enredo se reporta a épocas passadas (em relação ao período em que foi produzido, e não ao do espectador) são, como quaisquer outros, também documentos do período de sua produção. E esse enfoque jamais pode ser perdido, mesmo que o interesse do observador não se concentre nesse período.

A realização de um "filme histórico" sempre implica em seleções, montagens, generalizações, condensações, ocultações quando não em invenções ou mesmo falsificações. Dessa forma, o que deve ser buscado em um "filme histórico" não é a "verdade histórica" contida nele, mas a verossimilhança com o fenômeno histórico que retrata (MONTERDE, 1986, p.102-4).

É com base nos pressupostos que apresentamos que iniciaremos agora uma digressão pelos dois trabalhos cinematográficos de Bertolucci.

\section{O FILME “ANTES DA REVOLUÇÃO”}

Antes da Revolução (Prima della Rivoluzione, Itália, 1964, 1,55h) é um filme emblemático sobre a juventude revolucionária dos anos 60 , a primeira obra-prima de Bernardo Bertolucci e, talvez, o seu mais importante filme, baseado no romance "A Cartuxa de Parma", do escritor francês Stendhal.

É um filme típico dos anos 60 , a década da renovação da linguagem cinematográfica, da procura de uma expressão longe dos cânones estabelecidos, quando se queria, intensamente, "romper" com as estruturas acadêmicas da linguagem fílmica. O tempo, juiz supremo, se encarregou de separar o joio do trigo, mas Antes da Revolução, revisto hoje, conserva um impacto e um frescor surpreendentes. É um cinema de invenção de fórmulas, de mergulho intenso nas interrogações da vida, de perplexidade ante o estarno-mundo.

Filmado em Parma, uma cidade das raízes de Bertolucci, se constitui num ato de amor que a ela the dirige e que está plasmado no plano inicial, quando um travelling irrompe na sua praça principal, revelando a sua beleza, a sua arquitetura e a sua poesia. Um filme arrebatadoramente romântico, 
mostrando-nos a rebelião de um jovem contra a vida burguesa e sua desilusão com o comunismo.

Um domingo de Abril de 1962 em Parma, Fabrizio observa um mundo no qual se sente estrangeiro. É um jovem de 22 anos, cheio de contradições, pois passa por uma fase de indecisão política e afetiva e que funciona como o alter ego do cineasta, inclusive num momento no qual discute com o amigo a função do cinema na sociedade contemporânea. Descobre que não é fervoroso o bastante para ser um revolucionário, que está demasiadamente envolvido na beleza anterior à revolução. Tem "uma nostalgia do presente". Este jovem marxista - nesta época, vale lembrar, Bernardo Bertolucci pertencia ao Partido Comunista Italiano - cujo guia ideológico, mentor intelectual, é Cesare, um professor universitário. Ele sofre uma grave crise após o suicídio de Agostino, seu melhor amigo, um revoltado que fugiu de casa dos pais e que acompanhava frequentemente Fabrizio, buscando sua amizade. Quando Agostino é encontrado morto, afogado na correnteza de um rio, Fabrizio interroga-se sobre as razões do seu falecimento, entrando num processo de angústia. Acaba de romper com Clelia, uma jovem de boa família, que pouco se interessa pelos discursos políticos que ouve. Numa tarde, Fabrizio surpreende sua tia Gina, uma mulher bem mais velha e extremamente neurótica, aceitando as propostas de um desconhecido. Descobre-se ciumento, mas a sua tia, por compaixão, sabe consolá-lo, aceitando ter um caso com o sobrinho. Mas ela foge de Parma com Cesare para desespero de Fabrizio.

No fim do verão, Fabrizio, durante uma festa do Unitá (jornal do partido comunista italiano), sente-se ao mesmo tempo adulto e desiludido com o marxismo. Sua reconciliação com Clelia faz-se no Teatro Regio, durante uma representação de "Macbeth" de Verdi que inaugura a nova temporada lírica. Gina está presente no casamento de seu sobrinho. O revolucionário abandona, então, seus sonhos revolucionários e se dá por vencido. Ao depor as armas, decide-se aburguesar, aceitando um casamento que o integra, definitivamente, ao mundo da burguesia.

Se há um tema específico no filme, é o da existência e futuro do individual no interior de um momento efêmero, e o futuro desse próprio momento dentro de um processo histórico maior. Bertolucci usa a convencional 
dicotomia - romance e revolução - mas a disfarça num impressionante relato novelesco.

Bertoluci nos remete á inevitável indagação sobre o modo como se adquire uma cultura política. Quais são as particularidades de tal aprendizagem? Podemos seguir a análise piagetiana do desenvolvimento cognitivo na criança, procurando inspiração para examinar as etapas da maturação política, durante estes "anos impressionáveis" que são os da juventude - entendidos aqui como fase da vida?

Certamente, é principalmente para contestar, para recusar e rejeitar, que jovens se mobilizam, nomeadamente neste posicionamento tão ostensivo de engajamento que é a manifestação. Esta "razão manifesta", não específica dos jovens, mas que se tornou familiar durante a segunda metade do século $\mathrm{XX}$, quebra um outro mito, o da fraca relação entre jovens e política, pondo frontalement em questão o famoso ditado da "despolitização dos jovens.

A despeito dos aparelhos (algozes) e suas políticas de catequese (e aniquilamento), a juventude (por natureza humanista, pacifista, ecológica, ética) prossegue, é o mito mais maravilhoso de todos aqueles que simulam esta membrana precária a que chamamos realidade.

Mas, ou não fosse a segunda geração italiana marcada pelo empenhamento político, Antes da Revolução é, como referimos, um filme sobre a educação política, o culminar dos paradoxos experimentados por um jovem burguês adepto dos ideais marxistas. Fabrizio, o jovem intelectual que, inicialmente, é um fervoroso adepto do ideário de esquerda e que, paulatinamente, cede, conformando-se ao ponto de aceitar as instituições que o rodeiam.

\section{O FILME "O CONFORMISTA"}

Em 1970, Bernardo Bertolucci realizou O Conformista (Il conformista, 1,54h), uma competente adaptação literária de um romance de Alberto Moravia.

Constitui um bem elaborado estudo do caráter de um fascista que encontra no conformismo a válvula de escape para as obsessões homoeróticas 
supostamente adquiridas em um episódio de abuso sexual na infância. Enquanto que o romance de Moravia assenta em uma modalidade puramente linear de narração, começando com a infância de Marcello Clerici e evoluindo até à queda do governo de Mussolini, Bertolucci começa seu filme com os momentos finais, com Marcello, o personagem principal, esperando, em um quarto de hotel em Paris, uma chamada telefônica que o encaminhará ao homicídio de um professor.

O filme opõe magnificamente o regime fascista italiano a um personagem freudianamente torturado, sexualmente reprimido, que ingressa na polícia política do fascismo quase que inadvertidamente; ele se deixa levar e é atropelado pela história.

Crítica perspicaz à ditadura de extrema direita e de seu efeito sobre o ser humano, o filme de Bertolucci apresenta-se, sobretudo, como um cuidadoso estudo de um personagem.

O filme é um estudo de caso na psicologia do fascismo: Marcello Clerici é um homem burocrático deformado por uma família disfuncional da classe média e por um traumatismo sexual da infância.

O personagem, sob o sentimento de culpa por um crime, afinal, inexistente, recalca, de fato, o seu "desvio" sexual. Essa cobertura permite-lhe assumir papéis "viris" para os quais não foi talhado. O fascismo, no seu histerismo de falsa virilidade, foi a sua oportunidade para encontrar uma norma que correspondesse à sua vida sequestrada.

O Conformista é, na realidade, um estudo sobre um homem e sobre uma sociedade. É igualmente um estudo sobre um homossexual reprimido, cuja determinação em manter a respeitabilidade a todo o custo, o leva a aceitar o recrutamento por uma organização fascista de espionagem como objetivo de realizar uma terrível missão que acredita lhe permitirá expiar um estarrecedor incidente ocorrido na juventude.

No fim do filme, volvidos uns anos, já com um filho e vivendo uma lide familiar comum, o fiel do Duce Mussolini assiste, igualmente impassível e conformado, à queda do regime fascista no qual estava inserido. O seu plano toma imediatamente forma, sabendo desde logo que não será atingido pela fúria socialista. Na rua para onde se dirige, uma multidão arrasta os membros 
de uma estátua mutilada do Duce, numa antecipação da morte do líder fascista italiano. O seu plano começa aí, no meio da gente, ao negar-se fascista e ao acusar outros de o serem, exaltado por se reencontrar novamente com o seu passado, personificado pelo motorista que o seduziu e que ele julgava ter morto.

A dupla trajetória de Marcello faz lembrar a inevitável queda de Mussolini. Desencadeia-se um processo irreversível da autodestruição, no qual seu passado incomodo e seu presente moralmente corrompido colidirão num turbilhão de esmagamento das contradições pessoais.

O conformismo retira das pessoas qualquer crença nas condições de mudança, como se qualquer iniciativa fosse em vão. A participação política do indivíduo depende de inúmeros fatores e não somente, e talvez nem mesmo de forma particularmente significativa, de seu nível de desenvolvimento moral. Mas, de um país povoado por cidadãos capazes de raciocínios sofisticados em questões morais, é de se esperar uma participação de qualidade. Ou seja, é de se esperar que os indivíduos sejam capazes de participar de discussões e de chegar a compromissos que reduzam os conflitos e aumentem o nível de equidade da sociedade.

Educar significa empurrar para o exterior, sair do conformismo, incitando à viagem pelo desconhecido, mesmo sabendo que isso representa a possível quebra dos laços que dão conforto. Partir exige um dilaceramento que arranca uma parte do corpo à parte que permanece ligada à margem de nascimento, à proximidade de parentesco, à casa e aos costumes próprios do meio, à cultura da língua e à rigidez dos hábitos.

Por outro lado, porém, é necessário prevenir os riscos da domesticação e do doutrinamento. Daí a importância da vigilância ética assegurada por uma consciência profissional crítica, reflexiva e atenta. $O$ educador não tem o direito de vedar ao aluno o acesso às portas do futuro possível, a pretexto da falta de convicção ou de empenhamento, mas, por outro lado, não pode tentar obter resultados a todo o custo, enveredando por manobras de sedução, de manipulação e de violência.

Respeitando as exigências evolução das profissões na sociedade do conhecimento, as novas deontologias devem procurar traduzir um perfil 
profissional marcado pelo sentido de autonomia, pela abertura em relação a situações novas e imprevisíveis e pelo espírito inconformista que leva cada um a empenhar-se em processos de permanente aperfeiçoamento e busca. Só assim, a educação poderá assumir com sentido de dignidade e responsabilidade, a tarefa de ajudar a dar rosto ao futuro.

A verdade é que o autoritarismo, todos o sabemos, mata, em princípio, a autonomia. O que o autoritário pretende, com efeito, não é que o outro seja autônomo, mas obediente; não que pense por si, mas que acredite; não que critique, mas que absorva; não que aja segundo a sua consciência, mas que se conforme à norma. $O$ autoritarismo cria escravos, não homens autônomos. Cria Marcellos Clericis, como esse personagem conformista tão bem retratado por Bertolucci.

\section{Alguns desdobramentos das tramas cinematográficas de Bertolucci: desafios para os educadores}

Em uma boa parte de seus filmes, sobretudo estes que analisamos, Bertolucci optou por um tom intimista e cotidiano, mas seus personagens permaneceram vinculados a contradições políticas. Sua obra está impregnada por uma perspectiva histórica, com frequente recurso à memória e utilizando uma atitude crítica em relação aos problemas sociais, econômicos e políticos. Seu olhar é construído através de uma linguagem poética que transcende certos códigos consagrados e habituais do cinema.

Fica claro que a política é preponderante nos dois filmes. Em maior ou menor grau, as relações afetivas/amorosas dos personagens costuram todas as tramas.

Importa salientar que a História assume dimensões oficiais e memórias dirigidas e também de silenciar sobre acontecimentos e de impedir a manifestação das memórias dos segmentos sociais ou "minoritários", ou "subalternos" ou "vencidos" (Delgado, 2006, p. 49).

É este segundo caso que precisará ser mais pesquisado, pois ao contrário do primeiro, sua abordagem tem sido menos trabalhada. 
Por ora, apenas faremos alguns questionamentos: Que desafios se colocam ao professor no tratamento do diálogo entre política e História? Será que ele deve ser apenas um professor "ensinante", ou ao contrário deverá pautar-se por uma visão sócio crítica? O que será preciso lembrar do processo histórico? Que estratégias utilizar para trazer à tona até mesmo as mínimas experiências do aprendizado da História?

Perguntas, mesmo que inquietantes, precisarão ser feitas: Como ignorar o registro de visões de personagens ou testemunhas da História, nem sempre considerados pela História oficial? Como possibilitar o registro de versões alternativas às da História predominante? Como trabalhar a relação dialética entre os dispositivos de emancipação e as relações do poder político? Como incorporar estudos sobre o ato de lembrar, sobre a memória, por forma a ampliar a experiência educativa? Como trabalhar a memória política dos professores por forma a criticar, criar e produzir novas leituras do processo histórico?

Em termos de humanidade, nada está garantido à partida. A consciência deste fato convoca os educadores para o exercício de uma responsabilidade pessoal fundada numa memória social critica e ativa.

A educação deve manter o passado vivo, mas só o conseguirá alimentando o exercício de uma memória prospectiva e crítica, consolidada no diálogo entre diferentes modos de recordar. O passado pode então tornar-se presente, ajudando a despertar consciências capazes de se deixarem afetar pelo trágico dos acontecimentos.

Não é de hoje que os historiadores em geral e os professores em particular, demonstram ter clara consciência do caráter provisório, parcial e imperfeito do conhecimento produzido a partir de pesquisas anteriores. Admitir isso, entretanto, não deve colocar os educadores à beira do abismo do relativismo levado às últimas consequências. Significa apenas que não alimentamos ilusões quanto aos limites que os vestígios do passado impõem à nossa interpretação; não significa que abdicamos da intenção de produzirmos conhecimento, calcado em dados verificáveis.

Agora que a trama se "encerrou", o espectador (estamos imaginando-o como professor ou historiador) se interrogue sobre as 
implicações de "fazer história" que exige, dos mais sensatos, agudeza de espírito, sagacidade, perspicácia e um mergulho profundo nos arquivos da memória muitas vezes lacrados por "guardiães oficiais". Para conseguir esclarecer certos fatos, o historiador/professor tem que se transformar em um militante das liberdades de informação e de expressão, indício de sentimentos ou de caráter. Deve, numa sequência, permitam-nos a prescrição, constranger a evidência a partir da regulação das provas, tendo em vista o aprimoramento da verdade em todas as suas dimensões.

\section{REFERÊNCIAS}

DELGADO, Lucília de Almeida Neves. História oral: memória, tempo, identidades. Belo Horizonte: Autêntica, 2006.

FERRO, Marc. Cinema e História. Rio de Janeiro: Paz e Terra, 1992.

MONTERDE, J. E. Historia, cine y enseñanza. Barcelona: Laia, 1986. p.1024.

WHITE, Hayden. Ficción histórica, historia ficcional y realidade histórica. Buenos Aires: Prometeo Libros, 2010. 